\title{
Modeling the dispersion of drilling muds using the bblt model: the effects of settling velocity
}

\author{
Haibo Niu ${ }^{a}{ }^{a}$, Adam Drozdowski $^{b}$, Tahir Husain $^{a}$, Brian Veitch $^{\mathrm{a}}$, \\ Neil Bose ${ }^{c}$, and Kenneth Lee ${ }^{b}$ \\ ${ }^{a}$ Memorial University of Newfoundland, St. John's, NL, Canada, A1B 3X5 \\ ${ }^{\mathrm{b}}$ Bedford Institute of Oceanography, Dartmouth, NS, Canada, B2Y 4A2 \\ ${ }^{c}$ Australian Maritime College, Launceston, Tasmania, Australia, 7250
}

Key Words: drilling muds, dispersion, settling velocity, benthic boundary layer model

\begin{abstract}
The benthic boundary layer transport (bblt) model was widely used in the Atlantic Canadian offshore region to assess the potential impact zones from drilling wastes discharges from offshore oil and gas drilling. The current version of the bblt uses a single-class settling velocity scenario which may affect its performance, as settling velocity is size, shape and material dependent. In this study, the effects of settling velocity on bblt predictions were assessed by replacing this single-class settling velocity scenario with a multi-class size dependent settling velocity scenario. The new scenario was used in a hypothetical study to simulate the dispersion of barite and fine-grained drilling cuttings. The study showed that the effects of settling velocity on bblt predictions are spatial, temporal, and material dependent.
\end{abstract}

\section{Introduction}

The exploration and extraction of offshore oil and gas from beneath the ocean floor requires the disposal of drilling wastes such as spent drilling muds and rock cuttings. In most cases, offshore discharge is the least expensive and operationally simplest option for 
disposal of drilling wastes. However, the discharge of drilling wastes into the marine environment may pose adverse impacts, such as growth inhibition, mortality, and smothering, of marine organisms (Gordon et al., 2000; Cranford et al., 1999). In order to give operators and regulatory agencies the ability to assess the fate of drilling wastes under a variety of ocean conditions, mathematical modeling of the transport processes of drilling muds become important.

To date, a number of transport models for drilling wastes have been developed. These include: the Offshore Operators Committee (OOC) model (Brandsma and Saucer, 1983), bblt model (Drozdowski et al., 2004), NewCut model (Carles, 1996), MUDMAP model (ASA, 2006), ParTrack model (Rye et al. 2006), and PROTEUS model (Sabeur and Tyler, 2001). It was shown by a systematic review (Khondaker, 2000) that the ultimate accuracy of transport models relies on our knowledge of complex transport processes (such as settling and flocculation) of drilling wastes. This has been proved by the study of Carles and Bryden (1999) in which they found that the transport models are very sensitive to the type of settling equations used and therefore to the size and shape of the drilling cuttings. Khondaker (2000) also concluded there is no single, fully validated and universal drilling waste transport model, due to the still only partially understood transport processes.

Over the past two decades, extensive laboratory work has been conducted on the settling and flocculation processes of drilling wastes (Huang 1992; Chien, 1992; Gerard 1996; Carles, 2000; Curran et al. 2002; Niu et al., 2003) and this makes it possible to improve the transport models with the latest findings. The benthic boundary layer transport model, bblt, is a drilling waste transport model that considers the flocculation 
process and it has been used widely in the Atlantic Canadian offshore region as part of the environmental impact assessment for a number of projects (Gordon et al., 2000; Cranford et al., 2003; Thomson et al., 2000; Hannah et al., 2006; Tedford et al., 2002, 2003). A limitation of these previous studies is that they use of a single class of settling velocity, rather than multi-class settling velocities that are size and shape dependent. Therefore, the focus of the present paper is to use the bblt model with an improved settling velocity scenario to characterize the drift and dispersion of drilling wastes. The simulation results are compared with previously used settling velocity scenarios to show the effects of the new simulation strategy.

\section{bblt Model}

The bblt was developed by Bedford Institute of Oceanography to predict the transport and dispersion of particulate drilling wastes in the benthic boundary layer. The model assumes that all the discharge materials enter the benthic boundary layer and thus neglect the mechanism of plume surfacing. The primary mechanisms modeled by bblt are the horizontal dispersion due to the interaction of vertical mixing and vertical shear, mud flocculation and break-up, drift, and vertical mixing. The latest version, bblt v7.0, also integrated a biological impact module (Drozdowski et al., 2004).

The bblt is a particle based model which treats the drilling wastes load mass $M$ as $N$ pseudo-particle packets with mass $m=M / N$ and settling velocity $w$. The basic output of the bblt is the time series packet positions, $X_{n}(t), Y_{n}(t), Z_{n}(t)$. The movement of the packets has two components: horizontal dispersion and vertical distribution. The horizontal dispersion of the packets is measured by the horizontal variance of the packets distribution $\sigma^{2}\left(\mathrm{~m}^{2}\right)$. The effective diffusivity $K\left(\mathrm{~m}^{2} / \mathrm{s}\right)$ is defined as (Csanady 1973) 


$$
K=\frac{1}{2} \frac{\partial \overline{\sigma^{2}}}{\partial t}
$$

where the overbar denotes a time averaging. In two dimensions, the variances, $\sigma_{\max }^{2}$ and $\sigma_{\min }^{2}$, along the major and minor axes of the horizontal projection of the distribution are calculated. The effective diffusivity for this case is defined as

$$
D=\sqrt{K_{\max } K_{\min }}
$$

where $K_{\max }$ and $K_{\min }$ are the effective horizontal diffusivities along the major and minor axes, respectively. The $K_{\max }$ and $K_{\min }$ are defined by equation (1).

The vertical distribution of the packets is parameterized by a sediment concentration Rouse profile $c(z)$ as

$$
c(z)= \begin{cases}c_{a}(a / z)^{p_{1}} & z \leq \delta \\ c_{\delta}(\delta / z)^{p_{2}} & z>\delta\end{cases}
$$

where $z$ is the vertical coordinates, $a$ is the sediment reference height below which the particle motion is negligible, $c_{a}$ is the reference concentration $c(a)$ at height $a, \delta$ is the height of the current-wave boundary layer, $c_{\delta}$ is the reference concentration $c(\delta)$ at height $\delta, p_{1}$ and $p_{2}$ are the Rouse numbers defined as

$$
p=\frac{w}{\kappa u_{*}}
$$

where the $\kappa$ is the von Karman constant $\kappa=0.4, w$ is the settling velocity, $u_{*}=\sqrt{\tau_{b} / \rho}$ is the friction velocity, $\tau_{b}$ is the magnitude of bottom stress, and $\rho$ is the density of sea water.

The settling velocity in the current bblt can be either fixed (typically $0.5 \mathrm{~cm} / \mathrm{s}$ or 0.1 $\mathrm{cm} / \mathrm{s}$ ) or stress dependent. The stress dependent settling velocity (as shown in Fig. 1) considers the flocculation effect by using a three-point velocity. It is assumed that the flocculation occurs instantaneously after discharge and the flocs have a fast initial settling 
velocity $w_{0}$ (typically $0.5 \mathrm{~cm} / \mathrm{s}$ ). The flocs will remain at this velocity until the friction velocity $u_{*}$ exceeds the critical value $u_{*}^{c}$, at which point the flocs break up into their individual components and settle at a very low velocity $w_{2}$ (typically $0.01 \mathrm{~cm} / \mathrm{s}$ ). When the velocity $u_{*}$ falls below the critical value $u_{*}^{c}$ again, the drilling wastes will be incorporated into the background marine flocs and settle at a speed of $w_{1}$ (typically 0.1 $\mathrm{cm} / \mathrm{s})$. Thereafter, the settling velocity will be either $w_{1}$ or $w_{2}$ depend on the value of $u_{*}$ (Drozdowski et al., 2004).

The bblt calculates the concentration (mass per unit volume) by counting the packets in a user specified volume, for example a cylinder of radius $r$, from $z_{1}$ to $z_{2}$. The bblt also allows the user to use a user defined rectangular grid to calculate the concentration.

\section{Simulation Strategy}

As the settling velocity equation used is very important for the accuracy of a drilling waste transport model (Carles and Bryden, 1999), the performance of the bblt is expected to be improved by replacing the current single-class settling scenario with a more validated multi-class size dependent scenario. A new simulation strategy is proposed in this paper as illustrated in Fig 2.

The first part of the new simulation strategy is characterizing the drilling wastes. This becomes essential because the settling velocity of drilling wastes depends on the particle size, shape, and type of drilling fluids used.

The discharge generally comprises drilling muds (or fluids) and drilling cuttings. The drilling fluids are a suspension of solids (mainly barite and bentonite) and dissolved material in a base of water, oil, or synthetic material. Although the material permitted for 
discharging varies from country to country and from case to case, most regulations permit four types of discharges: water-based muds (WBM); cuttings produced by using water based muds (WBC); synthetic-based muds (SBM); and cuttings produced by using synthetic based muds (SBC). The later two are only permitted in certain conditions. The particles modeled by the bblt were forced to agree with the Rouse vertical profile, thus a coarse particle with large settling velocity will hardly be moved by the bottom stress. Therefore, the bblt should only be used for WBM, SBM and the fine-grained portion of WBC and SBC. The cut-off size for WBC and SBC is case dependent. In this study, only the cutting particles with settling velocities less than $1.5 \mathrm{~cm} / \mathrm{s}$ are considered; this corresponds to about 70 percent of the total cutting mass according to the data of Rye et al. (2006).

Once the material is identified, information about the particle size distribution of the material is needed. This can be obtained either from measurements or from a database. An example of the measured particle size distribution for both drilling cuttings and barite is given in Fig 3. If the particle size distribution data is unavailable, a database software (Carles 2000) may be used to generate a distribution according to the drilling conditions (for example the size of well, depth of well, type of drill-bit, type of drilling muds used etc.). The whole discharge material can then be divided into $n$ classes of particles with diameter $d_{i}$ and weight $W_{i}(i=1, \mathrm{n})$.

According to the material, and particle size distribution, different settling velocity equations (as shown in Table 1) will be used for each of the $n$ particle classes.

The WBC and WBM (mainly barite) both have a particle structure. Once discharged, both the coarse (Diameter $>0.05 \mathrm{~mm}$ ) and fine (Diameter $<0.05 \mathrm{~mm}$ ) particles will 
descend independently at the early stage. The settling velocity correlation from Chien (1994) can be used for the individual particles. The equation is given in Equation 5:

$$
w=0.0002403 e^{5.03 \psi} \frac{\mu_{e}}{d \rho_{f}}\left[\sqrt{1+920790.49 e^{-5.030 \psi} d\left(\frac{\rho_{p}}{\rho_{f}}-1\right)\left(\frac{d \rho_{f}}{\mu_{e}}\right)^{2}}-1\right]
$$

where $\psi$ a sphericity factor, $\mu_{e}$ is the effective dynamic viscosity, $d$ is the nominal diameter of the particle, $\rho_{p}$ is the density of the particle, and $\rho_{f}$ is the density of the ambient water. The coarse particles tend to settle rapidly around the discharge point while the fine particles gradually start to collide together and form flocs which have faster settling velocities than their originally individual constituent particles. The laboratory equations developed by Huang (1992) can be used to simulate the settling of flocs, as shown in Equation (6):

$$
w=j d^{f}
$$

where $j$ is an empirical constant with values ranging from 12.85 to 23.26 , and $f$ is also an empirical constant with values ranging from 0.52 to 0.59 .

The discharged SBC behaves differently than WBC. The synthetic based fluid has low water solubility and it tends to bind the drilling cuttings and barite together. Therefore, SBC normally descend fast and will not spread in the water column. The equations by Niu et al. (2003) can be used to simulate the settling of coarse SBC particles, as shown in equation (7)

$$
w=\frac{-3 b \mu+\sqrt{9 b^{2} \mu^{2}+48 a\left(\rho_{p}-\rho_{f}\right) \rho_{f} g d^{3}}}{6 a \rho_{f} d}
$$

where $a$ and $b$ are constants dependent on the particle sphericity $\psi$. Niu et al. (2003) also give a settling velocity equation for fine $\mathrm{SBC}$ flocs, as shown in equation (8): 


$$
w=2.22 \times 10^{-4} G^{1.07} d^{\frac{1.84}{G^{0.32}}}
$$

where $\mathrm{G}$ is the shear rate or velocity gradient $(1 / \mathrm{s})$.

The input of bottom stress can be computed by using the SEDTRAN96 (Li and Amos, 2001) model with measured oceanographic data. The bblt model can then be executed for each of the $n$ particle classes by using settling velocity equations from Table 1. Total concentration can be obtained by taking the sum of the $n$ individual concentration outputs.

\section{Case Study}

To test the simulation strategy described above, a hypothetical study was performed using the data from the North Triumph site south of Sable Island off the south east coast of Canada. The dispersion of barite near this site has been studied by Hannah et al. (2003).

Although Carles and Bryden (1996) have concluded the dispersion models are very sensitive to settling velocity equations, it is still unclear to what degree the bblt will be affected by it. Therefore, a sensitivity study using only barite and eight different settling velocities was conducted to show the sensitivity of the bblt to settling velocity equations before conducting a full analysis using different types of drilling wastes and different classes of particle sizes.

The same discharge rates and the same friction velocity due to current and waves $\left(u_{*_{C W}}\right)$ and due to currents $\left(u_{*_{C}}\right)$ used by Drozdowski et al. (2004) was used for this study. The stress is plotted in Fig 4. The period simulated for the sensitivity study was 5 days. 
The results of the sensitivity study for this site are shown in Fig 5. It can be seen from the plot that bblt is very sensitive to the settling velocity. By increase the settling velocity from $0.1 \mathrm{~cm} / \mathrm{s}$ to $1.5 \mathrm{~cm} / \mathrm{s}$ (increased 15 times), the center of mass concentration (deposited solids in gram per square meter seabed) increased from $0.5 \mathrm{~g} / \mathrm{m}^{2}$ to about 20 $\mathrm{g} / \mathrm{m}^{2}$ (increased 40 times).

In order to get a result comparable to previous studies, the first set of simulations considered only the barite from WBM. The time series discharge of barite for this site is available from Drozdowski et al. (2004) and is presented in Fig 6. According to the particle size distribution of barite (as shown in Fig. 2), ten particle classes of equal percentage of weight were used (Table 2). For simulation 1, the total number of packets was 59935 and the mass associated with one packet was $3.536 \mathrm{~kg}$. Similarly, 59935 packets were used for each of the ten classes of simulation 2 and each packet had a mass of $0.3536 \mathrm{~kg}$. The total mass discharged for both simulations was the same.

To assign the initial settling velocity $w_{0}$ for flocs, the size of the flocs is needed. As the current version of the bblt does not have a flocculation process model, assumptions must be made for the floc size. According to Huang (1992), the floc size of WBM ranges from $30 \mu \mathrm{m}$ to $300 \mu \mathrm{m}$. It was assumed in this study that the $30 \mu \mathrm{m}$ floc was produced by the $0.7 \mu \mathrm{m}$ particle and the $300 \mu \mathrm{m}$ floc was produced by the $50 \mu \mathrm{m}$ particle. Linear interpolation was performed to derive floc sizes for other particles between $0.7 \mu \mathrm{m}$ and $50 \mu \mathrm{m}$. The $w_{0}$ was then computed using Equation (6). The $w_{2}$ in Table 2 was calculated using Equation (5). Because of the sphericity (in equation 5) distribution is unavailable, a mean value of 0.8 was used as suggested by Chien (1994). The $w_{0}$ for large flocs in Table 2 are smaller than the $w_{2}$ for their individual particles. The reason for this is that the floc 
has a porous structure which reduces its effective density. The settling velocity value for background marine flocs $w_{1}$ is the same as that used by Drozdowski et al. (2004).

The materials considered in the second sets of simulations (No.3 and 4 in Table 3) were fine-grain drilling cuttings ( $70 \%$ of total cuttings). The densities of the drilling cuttings are normally smaller than barite and therefore their settling velocities are also smaller. The information about the amount of discharged drilling cuttings is unavailable and a cutting to barite ratio of 8:1 was assumed based on Rye et al. (2006). For simulation 3, the total number of packets was 59935 and the mass associated with one packet was $19.801 \mathrm{~kg}$. Similarly, 59935 packets were used for each of the seven classes of simulation 4 and each packet had a mass of about $2.829 \mathrm{~kg}$. The total mass discharged for both simulations was the same.

\section{Results and Discussions}

The results for the first set of simulations for barite are shown in Fig. 7 and Fig. 8. Fig. 7 shows the predicted near bottom depth averaged concentration after 120 hours (5 days).

The barite was dispersed to the southwest with a very high concentration near the rig (East $0 \mathrm{~m}$, North $0 \mathrm{~m}$ ). Fig. 8 shows the concentration after 900 hours (37.5 days). It can be seen that the center of mass has moved to the northeast with a very low concentration near the rig.

Environmental Effects Monitoring (EEM) data are available for the North Triumph site. Barite concentration at 38 locations at distances from $250 \mathrm{~m}$ to $20 \mathrm{~km}$ to the rig were determined by sampling the bottom sediment and sampling the water and suspended particles at $0.5 \mathrm{~m}$ above seabed (Hannah et al., 2003). The data for sampling site NT- 
250-7-D3 (250 m southwest) and NT-5000-6-D3 (5000 m southwest) were used to compare with model predictions. The results are shown in Fig 9 and Fig 10.

It can be seen from the Fig 9 that the new settling velocity strategy does affect the concentration prediction at early stages of simulation (before day 286) for locations close to the discharge. The concentration predicted by the multi-class scenario (simulation 2) is much lower (about two-orders) than the single-class scenario (simulation 1). The reason is that the new strategy used a set of $w_{0}$ which are much smaller than the previously used typical value of $0.5 \mathrm{~cm} / \mathrm{s}$. It is also shown by Fig 9 that this effect becomes insignificant at the later stage of simulation. The concentrations for both simulations are about the same after day 301 . The is because of the initial flocs settling velocity $w_{0}$ was no longer in effect after the stress reached the critical value $u_{*}^{c w}$. This can also be seen from Fig. 10 for site NT-5000-6-D3. Overall, although a few sudden variations of concentration have been predicted over the 7 days EEM period, the majority of the predicted concentrations are in the same order as the measured values.

The simulation results for fine-grain drilling cuttings are shown in Fig 11 and Fig 12. For the same location NT-250-7-D3 (see Fig. 11), the simulation 3 is only slightly higher than simulation 4 at the early stages of discharge (before day 290). The concentrations lie between $10^{5} \mu \mathrm{g} / \mathrm{L}$ and $10^{6} \mu \mathrm{g} / \mathrm{L}$. This is different from the barite case in which the concentration from the new simulation strategy (No.2) is about two-orders smaller than the single class simulation (No.1). The predicted later stage concentration for cuttings is also different from that for barite. The cutting concentration predicted by simulation 4 is higher than that predicted by simulation 3 , while the barite concentration predicted by simulation 2 is about the same as simulation 1 . The reason is that in the early stage, 
although the $w_{0}$ in simulation 4 is still smaller than that for simulation 3 , the high settling velocity of the coarse particles in cuttings made the difference insignificant. In simulation 3 , the cuttings were dispersed away in later stage and resulted in a low concentration as a smaller $w_{2}$ were used. On the contrary, the higher $w_{2}$ for coarse particle in simulation 4 made them less dispersible and resulted in a high concentration.

For location NT-5000-6-D3 (see Fig. 12), because it is far from the rig, the effects of $w_{0}$ and $w_{2}$ become less important. Although the predicted concentrations are still different, they are of the same magnitude. This does not imply that the choice of settling velocity is not important for the simulation. This is only because the selected settling velocity (in Tables 2 and 3) in this study lies within the less sensitive region for bblt model. Fig 5 shows clearly that the bblt is more sensitive for $w$ greater than $0.1 \mathrm{~cm} / \mathrm{s}$ and less sensitive for $w$ smaller than $0.1 \mathrm{~cm} / \mathrm{s}$.

\section{Conclusions}

The single class settling velocity scenario has been replaced with a multi-class sizedependent settling velocity scenario. The new scenario was applied in a hypothetical study to model the dispersion of both barite and fine-grained drilling cuttings. The simulation showed that the new settling velocity scenario does affect the predicted concentration.

At locations close to the rig, the new settling velocity scenario predicted a much smaller barite concentration than the single-class settling scenario at the early stages of simulation. This is the result of the smaller $w_{0}$ that were used in the multi-classes scenario. The predicted concentrations from both scenarios are of same magnitude at the later stages because the $w_{0}$ is only in effect in the early stages when the bottom stress is 
less than the critical value. Same magnitudes of concentration were also predicted by both scenarios for locations far from the rig at later stages of simulation (the early stage concentrations at these locations are zero).

For drilling cuttings, the predicted concentration by the new multi-class scenarios is only slightly smaller than that predicted by the single-class scenario for locations close to the rig. This reduced difference between the two scenarios is due to the fast deposition of relatively coarse drilling cutting particles. Furthermore, the predicted concentration by the new multi-class scenarios is much higher than that predicted by the single-class scenario for locations close to the rig. The reason is that the large $w_{2}$ in the multi-class scenario makes the coarse particles remain at the site and results in a high concentration at later stage. On the contrary, the smaller $w_{2}$ in the single-class scenario makes the cuttings easily dispersed away and results in a low concentration at later stage.

Similar to the barite, approximately same magnitudes of cutting concentration were also predicted by both scenarios for locations far from the rig at later stages of simulation. This does not imply that the choice of settling velocity is not important for these far locations. This is only because the selected settling velocity (in Tables 2 and 3) in this study lies within the less sensitive region for the bblt model.

Finally, it should be pointed out that there is still disagreement about $w_{0}$ amongst researchers. The values used in this study were based on laboratory measurements (Huang, 1992, Niu, 2003), which are much smaller than that suggested by Milligan and Hill (1998). Future research on field observations of $w_{0}$ is needed to get more accurate values. 


\section{Acknowledgements}

The Natural Sciences and Engineering Research Council (NSERC) of Canada and the Petroleum Research Atlantic Canada (PRAC) provided financial support for this study.

\section{References}

Applied Science Associates (ASA). (2006). http://www.appsci.com/mudmap/index.htm.

Brandsma, M. G., Saucer, R. C. (1983). The OOC model: Prediction of short term fate of drilling fluids in the ocean. Proceedings of Mineral Management Service Workshop on Discharged Modeling, Santa Barbara, CA, US, February 7-10, 1983.

Carles, L. J. (1996). Simulating the dispersion of offshore drill-cuttings. M.Sc Thesis, Heriot-Watt University, U.K.

Carles, L. J. (2000). Physical characteristics and aquatic settlement properties of offshore drill-cuttings. PhD Thesis, Robert Gordon University, Aberdeen, Scotland, U.K.

Carles, L. J., Bryden, I. G. (1999). The sensitivity of a dispersion model to cuttings settling speeds. Society of Underwater technology Journal, 24, 19-24.

Chien, S-F. 1992. Settling velocity of irregular shaped particles. SPE paper No. 26121.

Cranford, P. J., Gordon, Jr, D. C., Lee, K., Armsworthy, S. L., Tremblay, G. H. (1999). Chronic toxicity and physical disturbance effects of water and oil-based drilling fluids and some major constituents on adult sea scallops (placopecten magellanicus). Marine Environmental Research. 48, 225-256.

Cranford, P.J., Gordon, Jr., D. C., Hannah, C. G., Loder, J. W., Milligan, T. G., Muschenheim, D. K., Shen, Y. (2003). Modelling potential effects of petroleum exploration drilling on northern geoges bank scallop stocks. Ecological Modelling 166, 19-39. 
Csanady, G. T. (1973). Turbulent Diffusion in the Environment. D. Reidel Publishing Company.

Curran, K., Hill, J. P. S., Milligan, T. G. (2002). The role of particle aggregation in sizedependent deposition of drill mud. Continental Shelf Research, 22, 405-416.

Drozdowski, A., Hannah, C., Tedford, T. (2004). bblt Version 7 user's manual. Canadian Technical Report of Hydrography and Ocean Science, 69 pp.

Gerard, A. L. D. (1996). Laboratory investigations on the fate and Physicochemical properties of drilling cuttings after discharged into the sea. Physical and Biological Effects of Processed Oily Drill Cuttings, E\&P Forum Report, Paper 3, 16-24.

Gordon, Jr., D. C., Cranford, P.J., Hannah, C.G., Loder, J.W., Milligan, T. G., Muschemheim, D. K., Shen, Y. (2000). Modelling the transport and effects on scallops of water-based drilling mud from potential hydrocarbon exploration on Geoges Bank. Can. Tech. Rep. Fish. Aquat. Sci. 2317, 115 pp.

Huang, H. (1992). Transport properties of drilling muds and Detroit River sediments. PhD Thesis. University of Santa Barbara, CA, U.S., May 1992.

Khondaker, A. N. (2000). Modeling the fate of drilling waste in marine environment - an overview. Computer \& Geosciences, 26, 531-540.

Li, M. Z., Amos, C. L. (2001). SEDTRAN96: the upgraded and better calibrated sediment-transport model for continental shelves. Computers \& Geosciences, 27, 619645.

Milligan, T. G., Hill, P. S. (1998). A laboratory assessment of the relative importance of turbulence, particle composition, and concentration in limiting maximal floc size and settling behaviour. Journal of Sea Research, 39, 227-241. 
Niu, H., Husain, T., Veitch, B., Bose, N. (2003). Transport Properties of Offshore Discharged Synthetic Based Drilling Cuttings, Proceedings of MTS/IEEE Oceans 2003 Conference, Sep 22-26, 2003, San Diego, CA, U.S., Vol 1, 411-416.

Rye, H., Reed, M., Frost, T. K., Utvik, T. I. R. (2006). Comparison of the ParTrack mud/cuttings release model with field data based on use of synthetic-based drilling fluids. Environmental Modelling \& Software, 21, 190-203.

Sabeur, Z.A., Tyler, A.O. (2001). "Validation of the PROTEUS Model for the Physical Dispersion, Geochemistry and Biological Impacts of Produced Waters," In Proceedings of the $5^{\text {th }}$ International Marine Environmental Modeling Seminar, Oct 911, 2001, New Orleans, Louisiana, USA, 209-228.

Tedford, T., Drozdowski, A., Hannah, C. G. (2003). Suspended sediment drift and dispersion at Hibernia. Can. Tech. Rep. Hydrogr. Ocean Sci. 227, 57 pp.

Tedford, T., Hannah, C. G., Milligan, T. G., Loder, J. W., Muschenheim, D. (2002). Flocculation and the fate of drill mud discharges. In: Spaulding M. L. (Ed.), Estuarine and Coastal Modelling: Proceedings of the 7th International Conference. ASCE, 294309.

Thomson, D. H., Davis, R. A., Belore, R., Gonzalez, E., Christian, J., Moulton, V. D., Harris, R. E. (2000). Environmental assessment of exploration drilling on Nova Scotia. Report prepared for Canada - Nova Scotia Offshore Petroleum Board and Mobil Oil Canada Properties, Shell Canada Ltd., Imperial Oil Resources Ltd., Gulf Canada Resources Ltd., Chevron Canada Resources, EnCana Petroleum Ltd., Murphy Oil Company Ltd., and Norsk Hydro Canada Oil \& Gas Inc. Report Prepared by LGL Ltd. Environmental Research Associates, LGL Report, TA 2281, p.25. 
Hannah, C. G., Drozdowski, A., Loder, J., Muschenheim, K., Milligan, T. (2004). An assessment model for the fate and environmental effects offshore drilling mud discharges. Estuarine Coastal and Shelf Science, 70, 577-588.

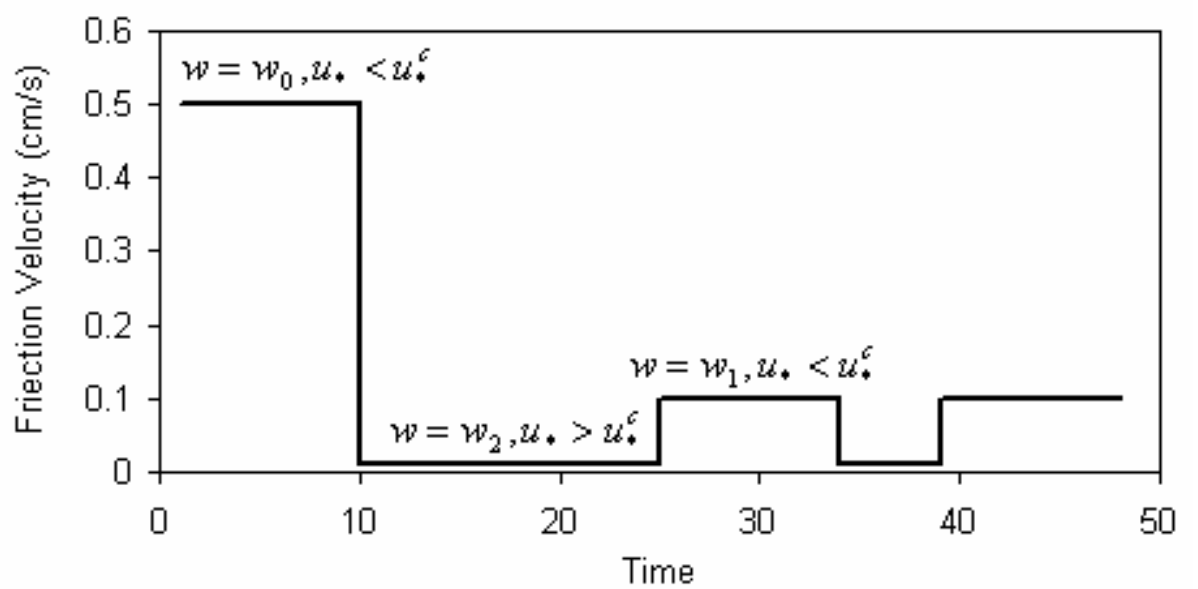

Fig 1. An illustration of the stress-dependent settling velocity (modified from Drozdowski et al., 2004) 


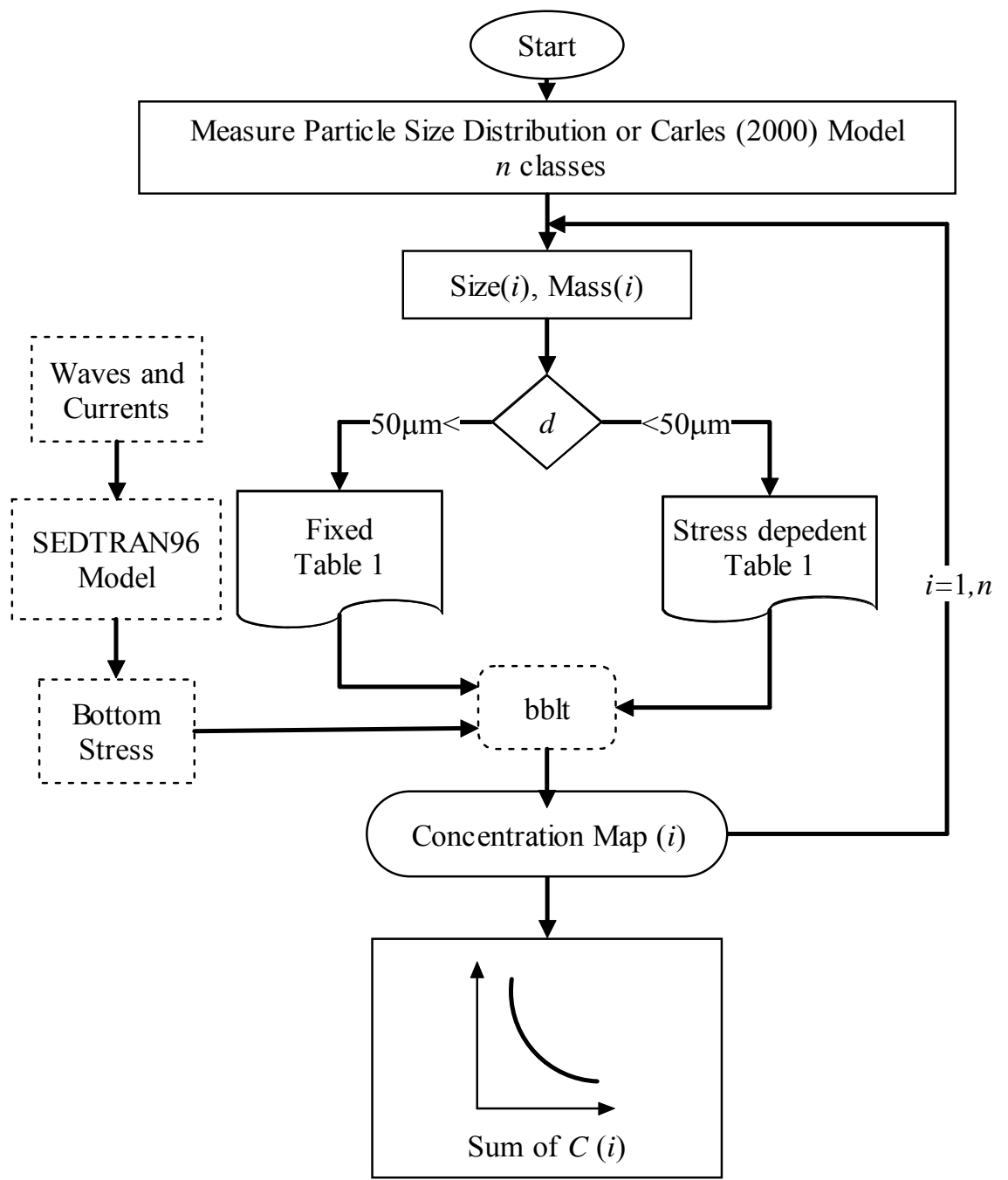

Fig. 2 bblt simulation strategy 


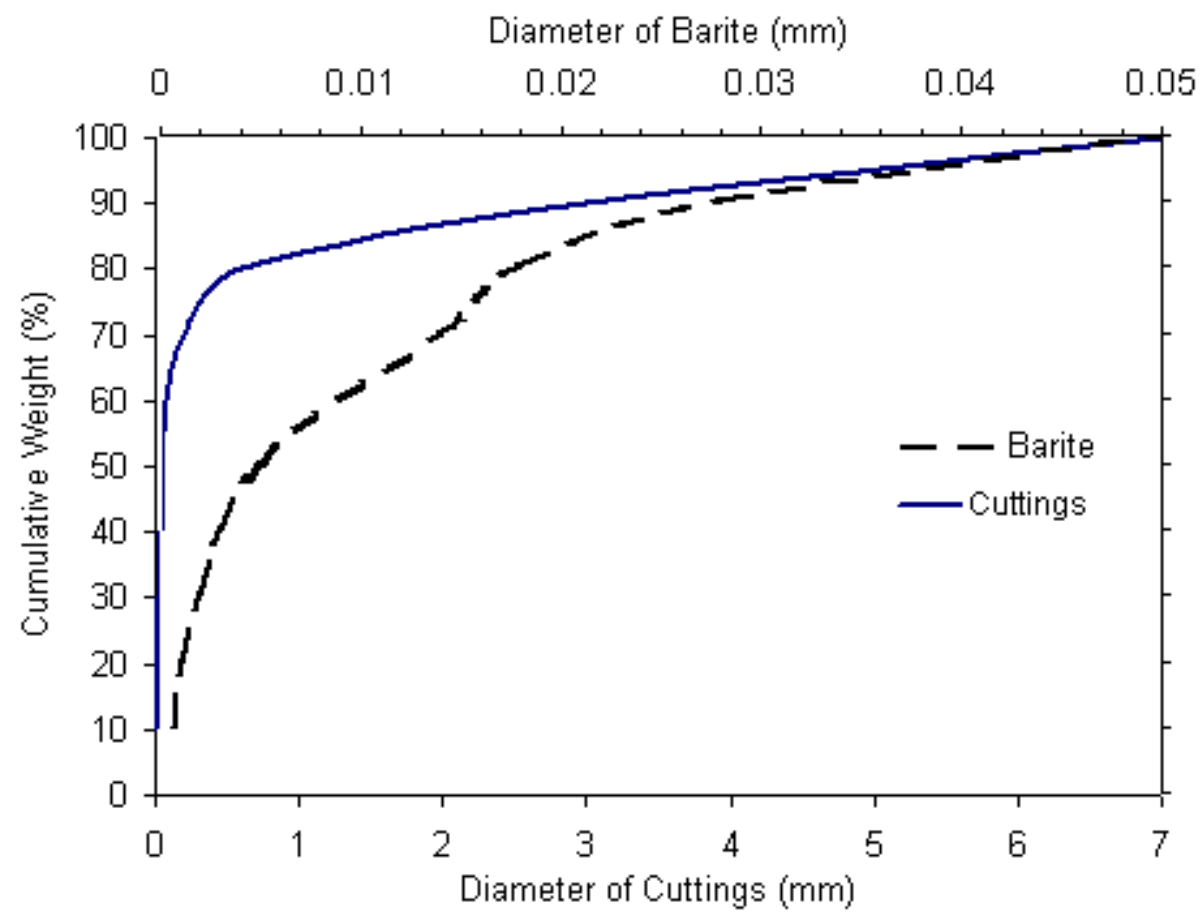

Fig 3. Particle size distribution according to Rye et al. (2006) 


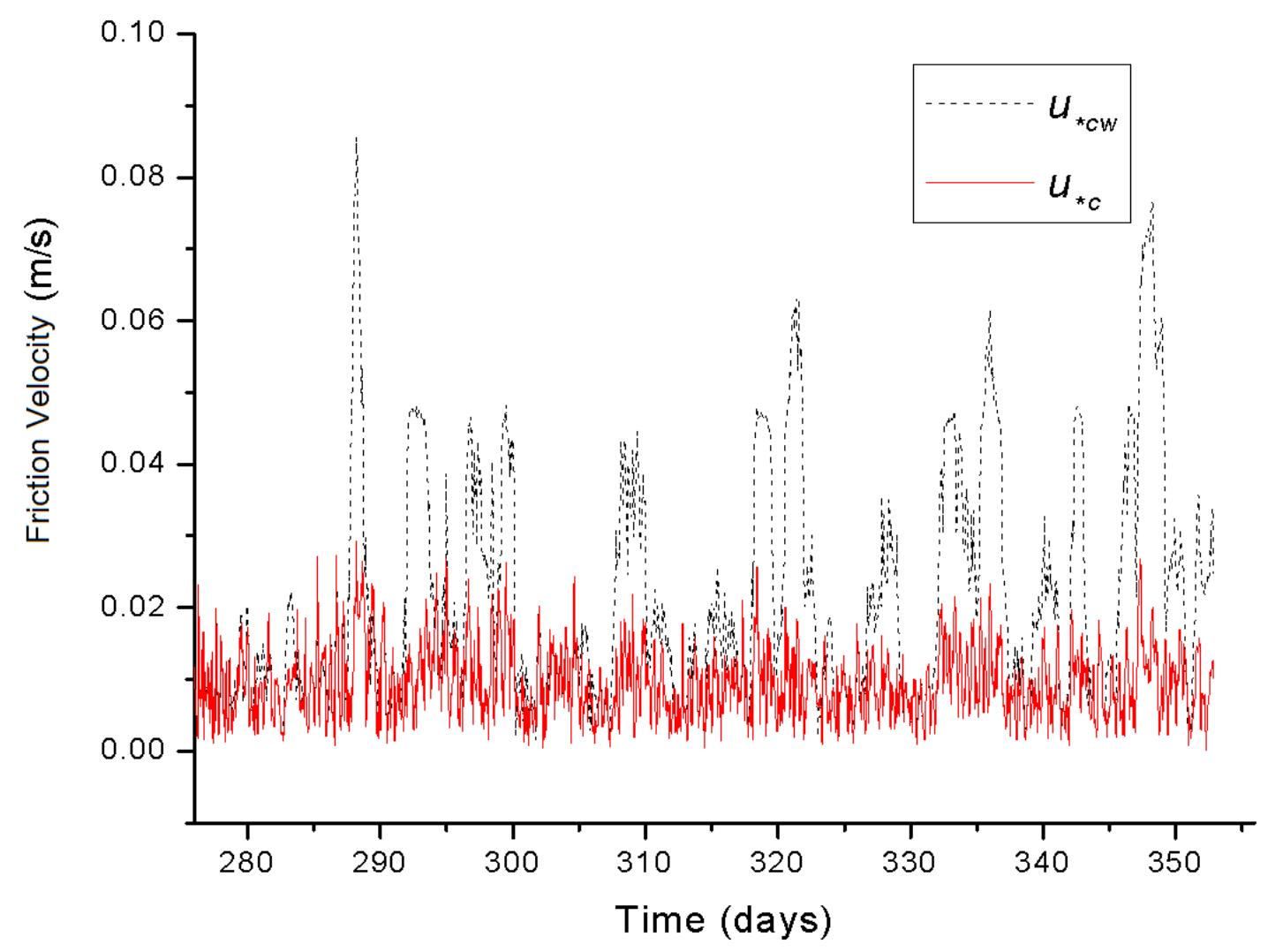

Fig. 4 Total stress due to current and waves $u_{*_{C W}}$ and due to currents $u_{*_{c}}$ 


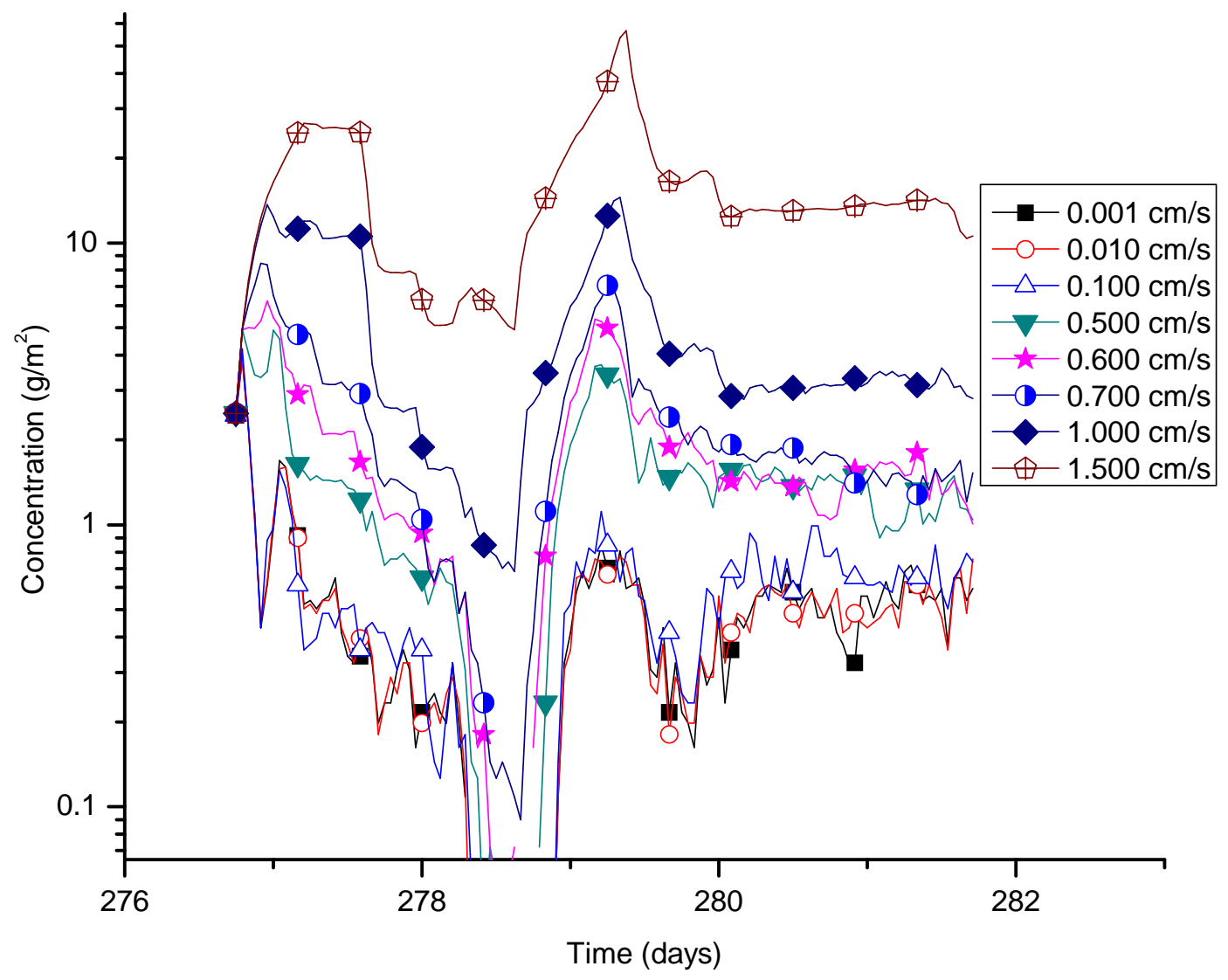

Fig. 5 Sensitivity of bblt to settling velocity 


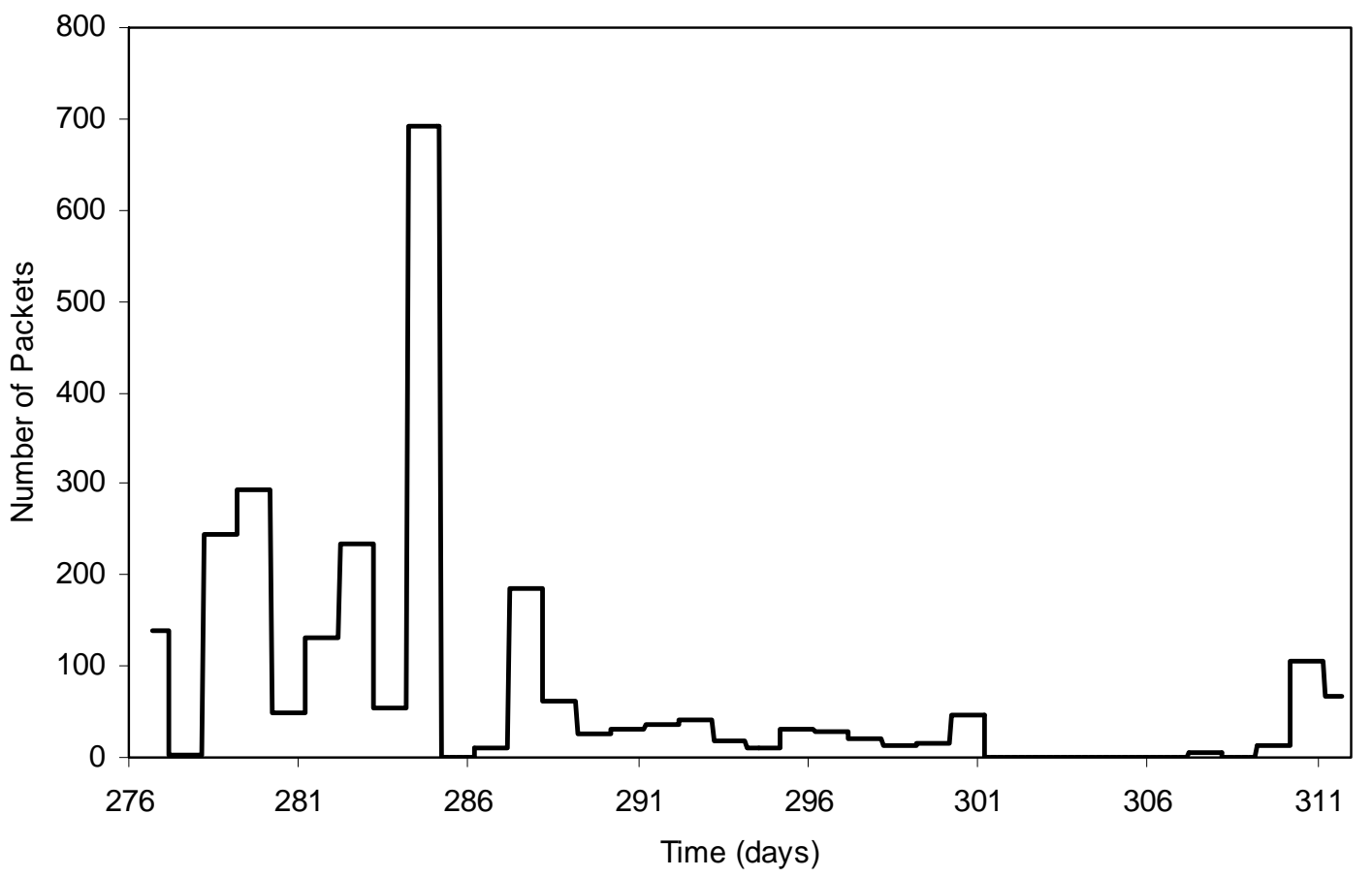

Fig 6. Discharge time series (data from Drozdowski et al., 2004) 


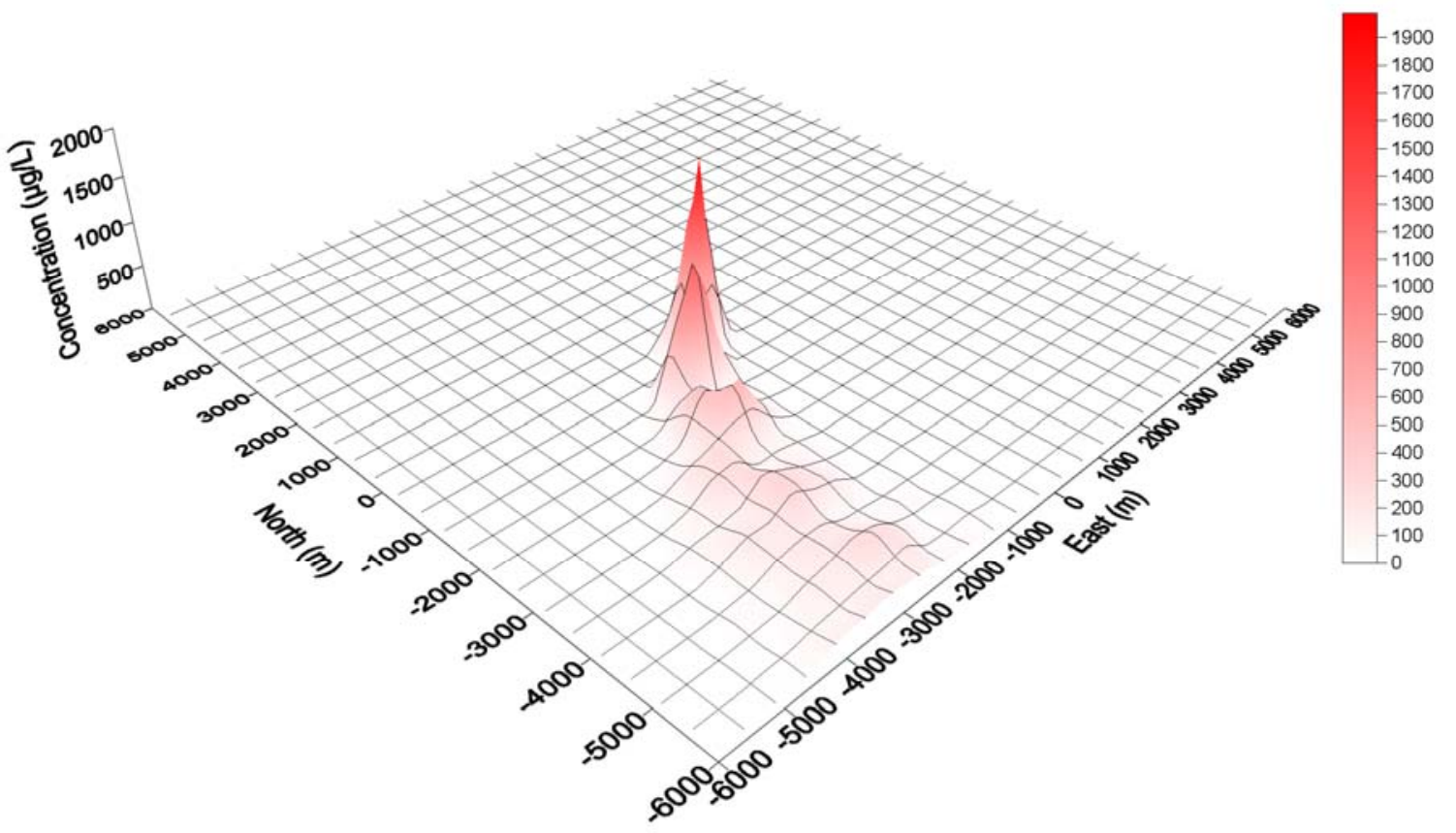

Fig. 7 Barite concentration plot (120 hours) 


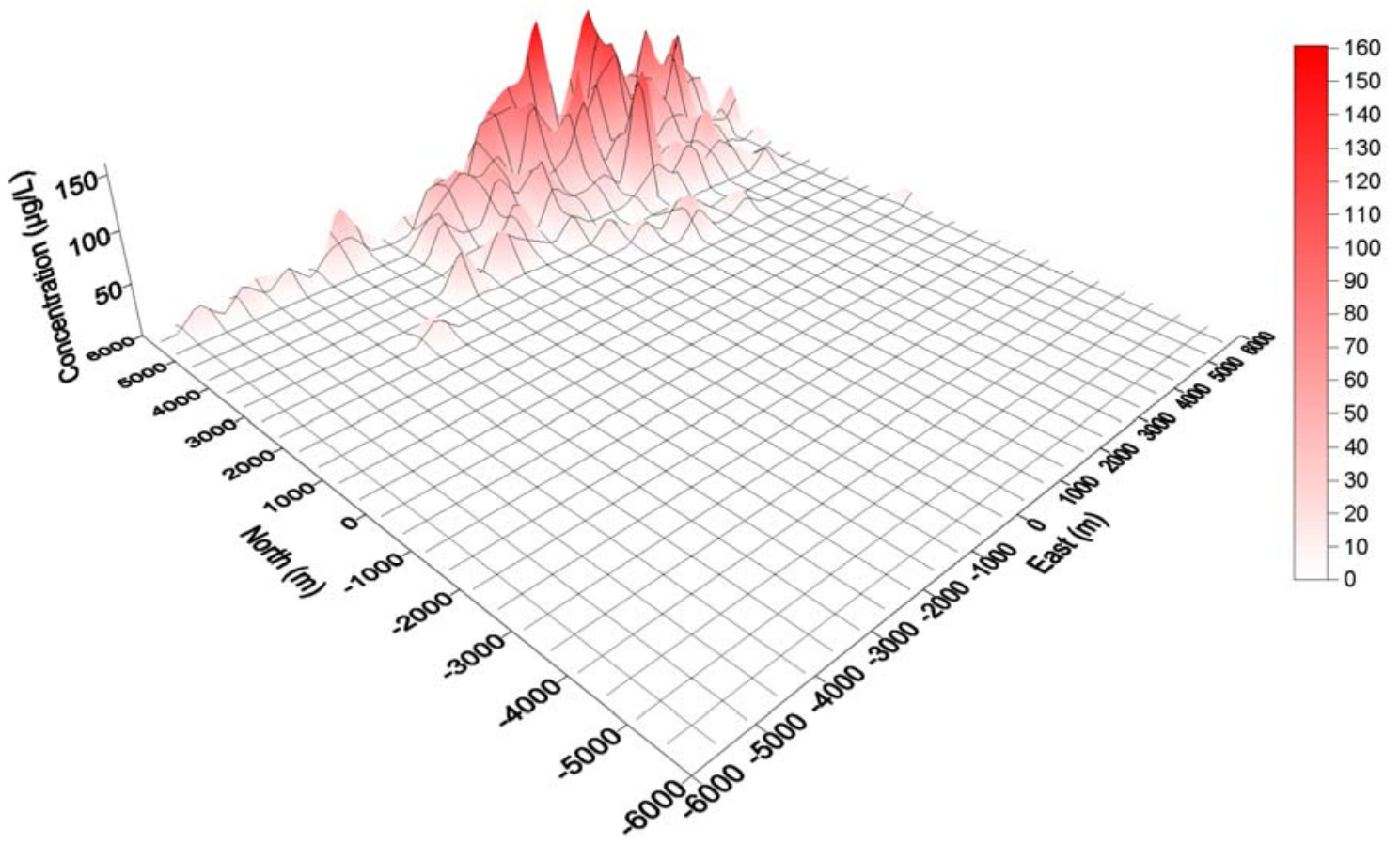

Fig. 8 Barite concentration plot (900 hours) 

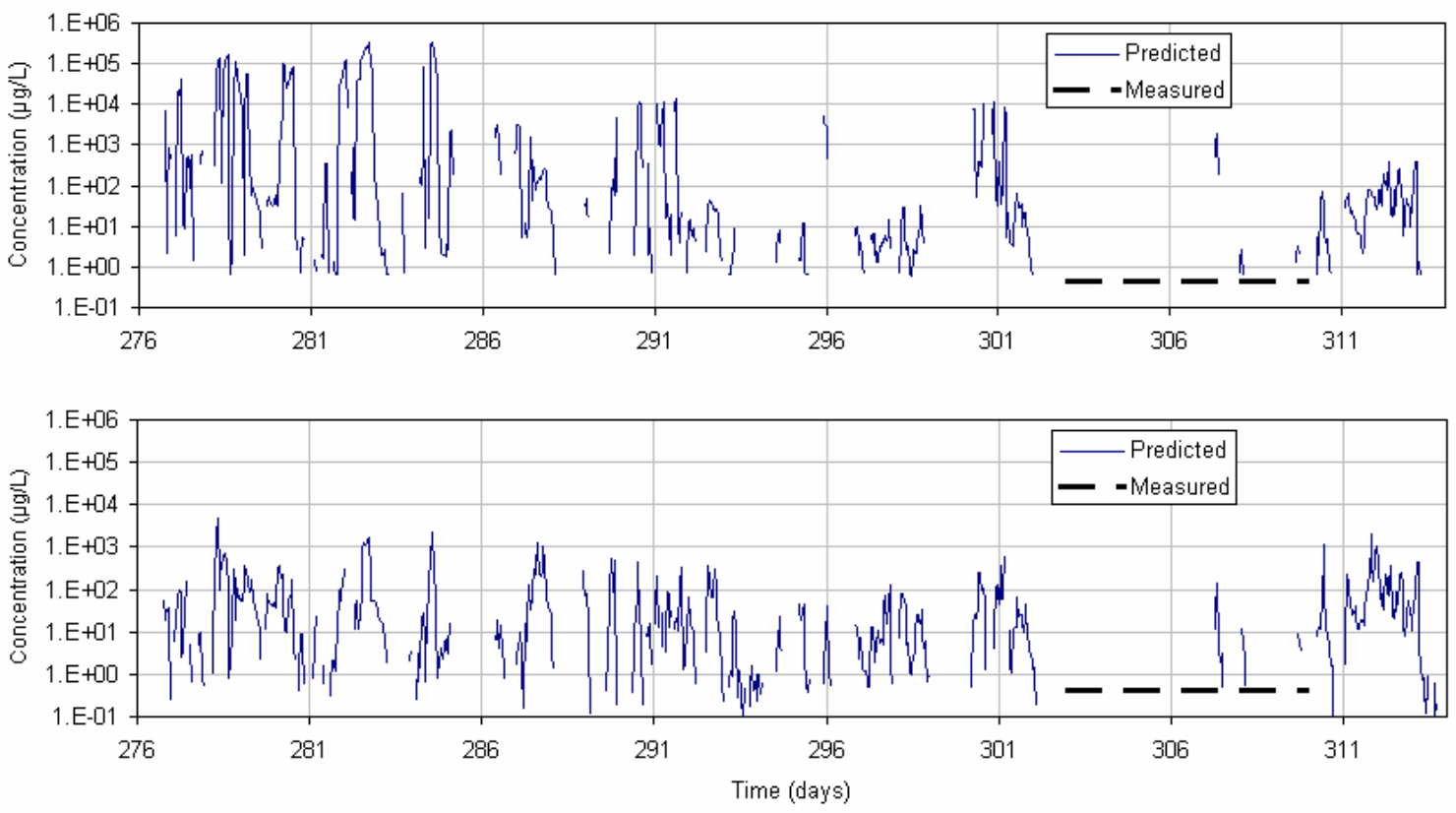

Fig. 9 Comparison of the EEM data with simulation 1 (a) and simulation 2 (b) for NT-250-7-D3 

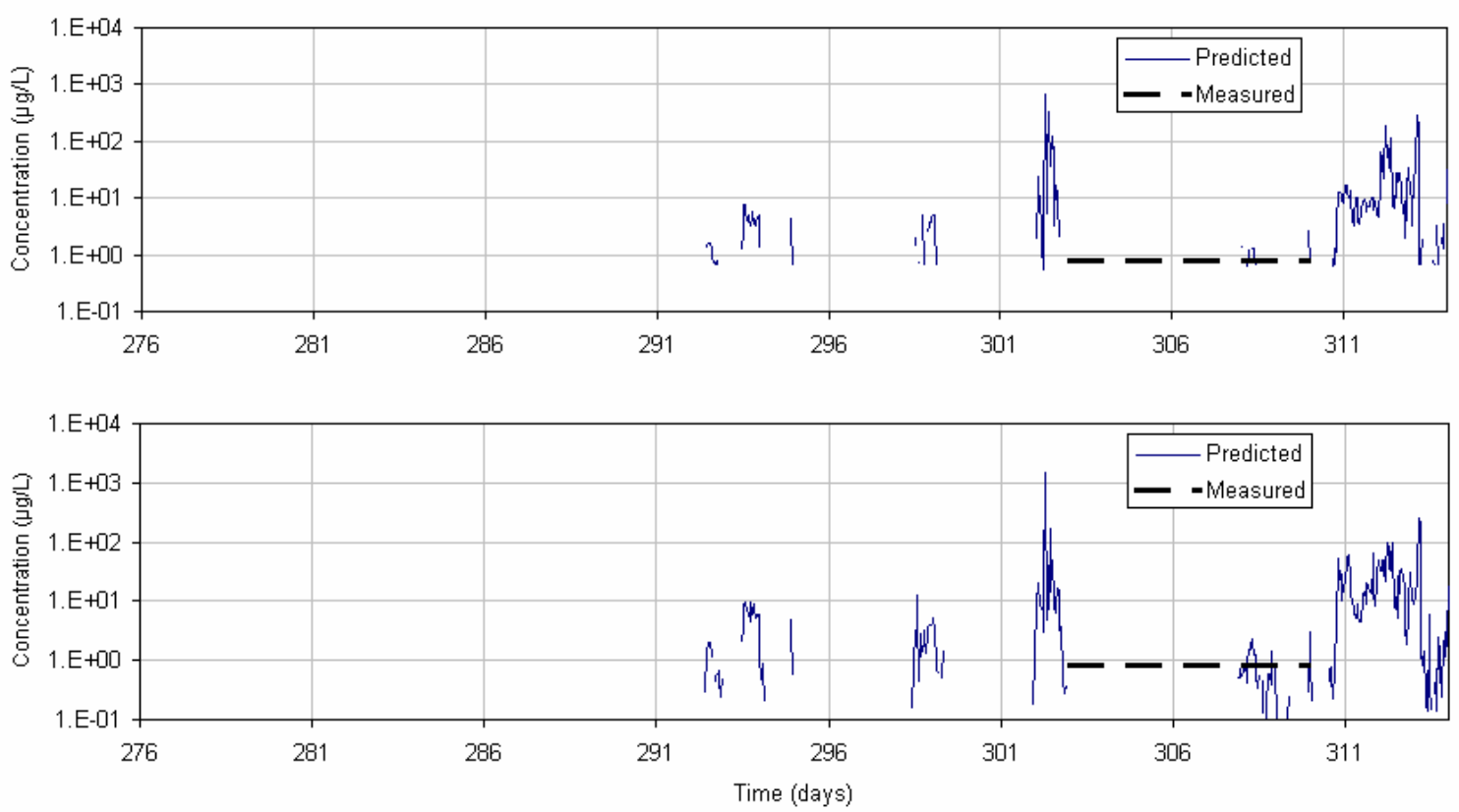

Fig. 10 Comparison of the EEM data with simulation 1 (a) and simulation 2 (b) for NT-5000-6-D3 

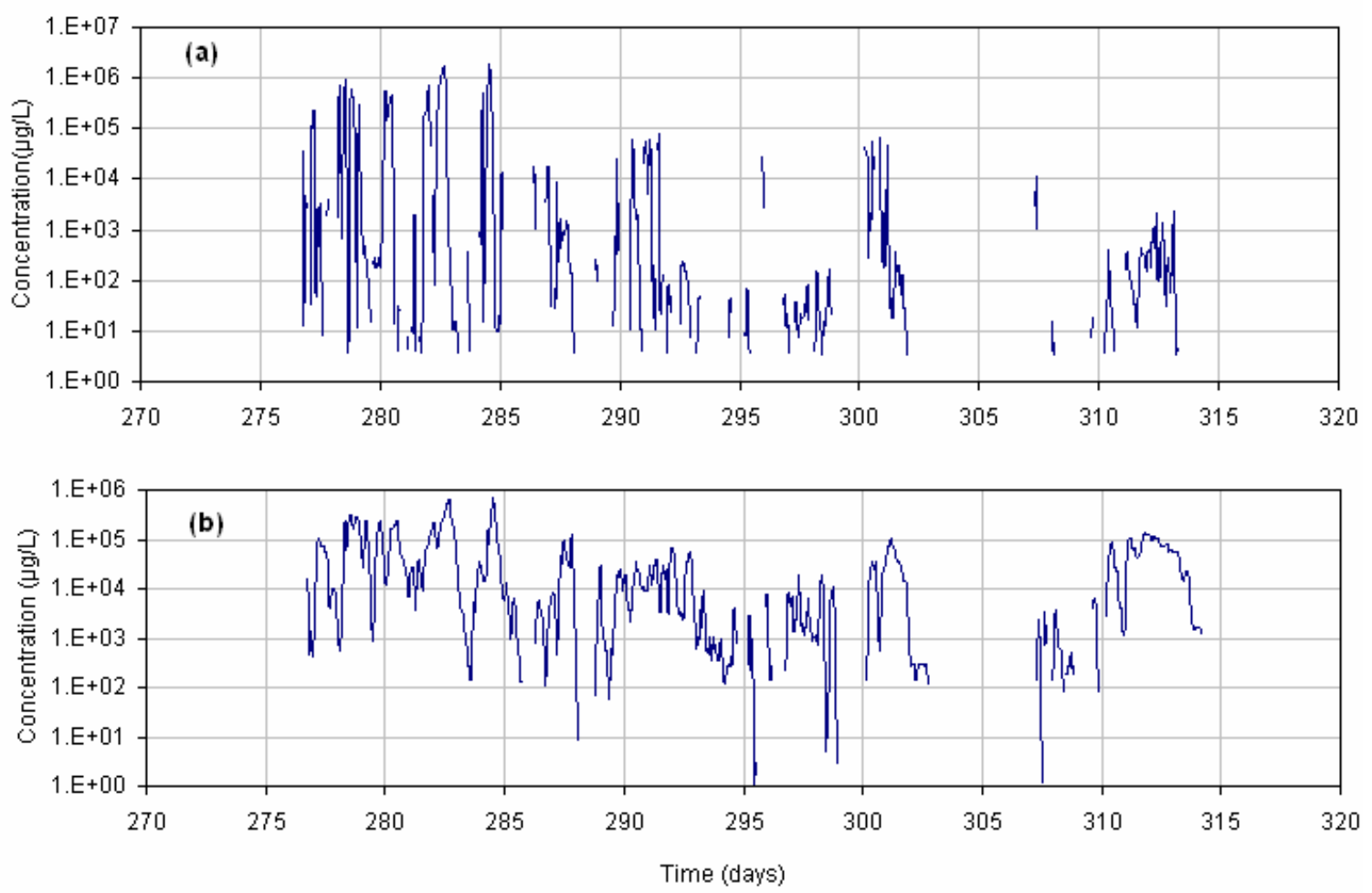

Fig. 11 Predicted concentration for NT-250-7-D3 by simulation 3 (a) and simulation 4 (b) 

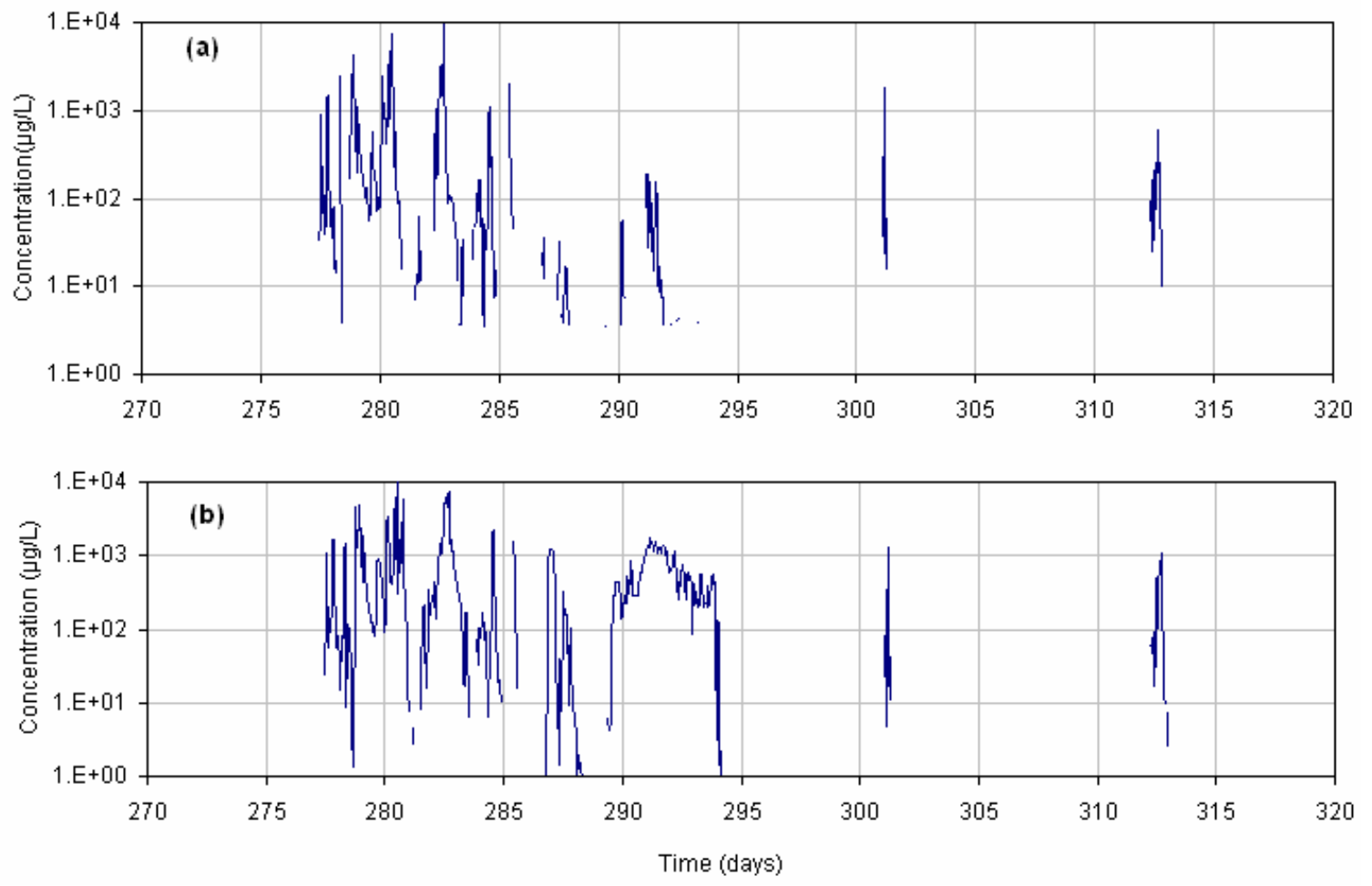

Fig. 12 Predicted concentration for NT-5000-6-D3 by simulation 3 (a) and simulation 4 (b) 
Table 1 . Settling velocity scenario

\begin{tabular}{ccccccc}
\hline Material & Sizes & Scenario & $w$ & $w_{0}$ & $w_{2}$ & $w_{1}$ \\
\hline \multirow{2}{*}{ WBF } & $>50 \mu \mathrm{m}$ & $\mathrm{F}$ & Equation (5) & & & \\
& $<50 \mu \mathrm{m}$ & $\mathrm{S}$ & & Equation (6) & Equation (5) & $0.1 \mathrm{~cm} / \mathrm{s}$ \\
WBC & $>50 \mu \mathrm{m}$ & $\mathrm{F}$ & Equation (5) & & & \\
& $<50 \mu \mathrm{m}$ & $\mathrm{S}$ & & Equation (6) & Equation (5) & $0.1 \mathrm{~cm} / \mathrm{s}$ \\
$\mathrm{SBC}$ & $>50 \mu \mathrm{m}$ & $\mathrm{F}$ & Equation (7) & & & \\
& $<50 \mu \mathrm{m}$ & $\mathrm{S}$ & & Equation (8) & Equation (5) & $0.1 \mathrm{~cm} / \mathrm{s}$ \\
\hline
\end{tabular}

* F - Fixed, S - Stress dependent

Table 2 Barite in drilling mud particle diameter, and settling velocity distribution

\begin{tabular}{ccccccccc}
\hline No & $\begin{array}{c}\text { Diameter } \\
(\mu \mathrm{m})\end{array}$ & $\begin{array}{c}\text { Weight } \\
(\%)\end{array}$ & Packets & $\begin{array}{c}\text { Packet } \\
\text { Mass }(\mathrm{kg})\end{array}$ & $\begin{array}{c}\text { Floc } \\
\text { Size } \\
(\mu \mathrm{m})\end{array}$ & $\begin{array}{c}w_{0} \\
(\mathrm{~cm} / \mathrm{s})\end{array}$ & $\begin{array}{c}w_{2} \\
(\mathrm{~cm} / \mathrm{s})\end{array}$ & $\begin{array}{c}w_{1} \\
(\mathrm{~cm} / \mathrm{s})\end{array}$ \\
\hline \multirow{4}{*}{1} & $\begin{array}{c}\text { Single } \\
\text { Size }\end{array}$ & 100 & 59935 & 3.536 & $\begin{array}{c}\text { Single } \\
\text { Size }\end{array}$ & $5.00 \mathrm{E}-01$ & $1.00 \mathrm{E}-02$ & $1.00 \mathrm{E}-01$ \\
& & & & & & & & \\
& 0.7 & 10 & 59935 & 0.3536 & 30 & $1.73 \mathrm{E}-02$ & $3.89 \mathrm{E}-05$ & $1.00 \mathrm{E}-01$ \\
& 1.0 & 10 & 59935 & 0.3536 & 32 & $1.79 \mathrm{E}-02$ & $7.93 \mathrm{E}-05$ & $1.00 \mathrm{E}-01$ \\
& 2.0 & 10 & 59935 & 0.3536 & 37 & $1.96 \mathrm{E}-02$ & $3.17 \mathrm{E}-04$ & $1.00 \mathrm{E}-01$ \\
& 3.0 & 10 & 59935 & 0.3536 & 43 & $2.13 \mathrm{E}-02$ & $7.14 \mathrm{E}-04$ & $1.00 \mathrm{E}-01$ \\
& 9.0 & 10 & 59935 & 0.3536 & 54 & $2.44 \mathrm{E}-02$ & $1.98 \mathrm{E}-03$ & $1.00 \mathrm{E}-01$ \\
& 9.0 & 10 & 59935 & 0.3536 & 75 & $2.98 \mathrm{E}-02$ & $6.42 \mathrm{E}-03$ & $1.00 \mathrm{E}-01$ \\
& 14.0 & 10 & 59935 & 0.3536 & 103 & $3.58 \mathrm{E}-02$ & $1.55 \mathrm{E}-02$ & $1.00 \mathrm{E}-01$ \\
& 10 & 10 & 59935 & 0.3536 & 125 & $4.01 \mathrm{E}-02$ & $2.57 \mathrm{E}-02$ & $1.00 \mathrm{E}-01$ \\
& 28.0 & 10 & 59935 & 0.3536 & 180 & $4.97 \mathrm{E}-02$ & $6.21 \mathrm{E}-02$ & $1.00 \mathrm{E}-01$ \\
& 10 & 59935 & 0.3536 & 300 & $6.73 \mathrm{E}-02$ & $1.98 \mathrm{E}-01$ & $1.00 \mathrm{E}-01$ \\
& Sum & 100 & & 3.536 & & & & \\
\hline
\end{tabular}

Table 3 Drilling cuttings particle diameter, and settling velocity distribution

\begin{tabular}{ccccccccc}
\hline No & $\begin{array}{c}\text { Diameter } \\
(\mu \mathrm{m})\end{array}$ & $\begin{array}{c}\text { Weight } \\
(\%)\end{array}$ & Packets & $\begin{array}{c}\text { Packet } \\
\text { Mass }(\mathrm{kg})\end{array}$ & $\begin{array}{c}\text { Floc } \\
\text { Size } \\
(\mu \mathrm{m})\end{array}$ & $\begin{array}{c}w_{0} \\
(\mathrm{~cm} / \mathrm{s})\end{array}$ & $\begin{array}{c}w_{2} \\
(\mathrm{~cm} / \mathrm{s})\end{array}$ & $\begin{array}{c}w_{1} \\
(\mathrm{~cm} / \mathrm{s})\end{array}$ \\
\hline 3 & $\begin{array}{c}\text { Single } \\
\text { Size }\end{array}$ & 100 & 59935 & 19.8016 & $\begin{array}{c}\text { Single } \\
\text { Size }\end{array}$ & $5.00 \mathrm{E}-01$ & $1.00 \mathrm{E}-02$ & $1.00 \mathrm{E}-01$ \\
& & & & & & & & \\
4 & 7 & 14.28 & 59935 & 2.828706 & 30 & $1.73 \mathrm{E}-02$ & $1.69 \mathrm{E}-03$ & $1.00 \mathrm{E}-01$ \\
& 15 & 14.28 & 59935 & 2.828706 & 80 & $3.08 \mathrm{E}-02$ & $7.74 \mathrm{E}-03$ & $1.00 \mathrm{E}-01$ \\
& 25 & 14.28 & 59935 & 2.828706 & 143 & $4.34 \mathrm{E}-02$ & $2.15 \mathrm{E}-02$ & $1.00 \mathrm{E}-01$ \\
& 35 & 14.29 & 59935 & 2.828706 & 206 & $5.39 \mathrm{E}-02$ & $4.21 \mathrm{E}-02$ & $1.00 \mathrm{E}-01$ \\
& 50 & 14.29 & 59935 & 2.828706 & 300 & $6.73 \mathrm{E}-02$ & $8.59 \mathrm{E}-02$ & $1.00 \mathrm{E}-01$ \\
& 75 & 14.29 & 59935 & 2.829036 & & & $1.93 \mathrm{E}-01$ & \\
& 200 & 14.29 & 59935 & 2.829036 & & & $1.29 \mathrm{E}+00$ & \\
& Sum & 100 & & 19.8106 & & & & \\
\hline
\end{tabular}

